\title{
Campylobacter fetus in Abomasal Fluid from Spontaneously Aborted Bovine and Ovine Fetuses
}

\author{
Gabriela Merker Breyer ${ }_{(0}^{1}$, Maria Eduarda Dias ${ }^{1}$, Luan Cleber Henker ${ }_{(2}^{2}$,

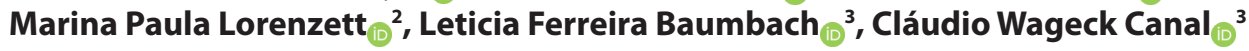

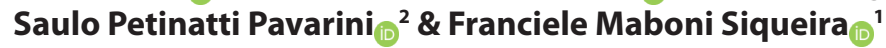

\begin{abstract}
Background: Pregnancy losses are a major concern in livestock industry due to their economic impact on producers. Campylobacter fetus subspecies fetus (Cff) and C. fetus subspecies venerealis (Cfv) are directly related to reproductive failures in ruminants. Cff colonizes the gastrointestinal tract of a wide range of hosts leading to abortion, while $\mathrm{Cfv}$ is restricted to genital tract being generally associated to infertility in bovine. Considering the great economic losses related to campylobacteriosis in cattle and ovine herds, this study aims to investigate the occurrence of C. fetus, considering Cff and Cfv subspecies, in bovine and ovine spontaneously aborted fetuses in state of Rio Grande do Sul, Brazil.

Materials, Methods \& Results: In this study, samples of abomasal fluid collected from 30 spontaneously aborted bovine $(\mathrm{n}=18)$ and ovine $(\mathrm{n}=12)$ fetuses were investigated for the detection of Campylobacter fetus throughout conventional PCR. Positive fetuses for $C$. fetus presence were further analyzed by molecular assays for Cff and Cfv detection, in order to determine subspecies identification. When available, samples of the main organs of the thoracic and abdominal cavities, as well as the brain, skeletal muscle, eyelid, skin, and placenta were collected for further histopathological analyses and bacterial culture, aiming to assess the presence of infection lesions and pathogens in those sites, respectively. Additionally, RT-qPCR assays were also performed for the detection of ruminant pestivirus, in order to detect bovine viral diarrhea cases. Throughout the present methodology, C. fetus was detected in the abomasal fluid samples of 2 bovine fetuses, being both identified as Cfv subspecies by PCR. Histopathological analyses demonstrated that macroscopic and microscopic changes found in the Cfv-positive animals were not either specific or directly related to Campylobacter infections. Moreover, no significant bacterial growth was observed in microbiological culture from the collected tissues, and both fetuses were negative for ruminant pestivirus. Differently, there was no detection of $C$. fetus in any of the analyzed ovine fetuses. Discussion: Considering that abortion diagnosis rates reported in cattle and sheep industry are highly variable among the published studies, and that abortion diagnoses are commonly inconclusive due to difficulties in sampling methodology and inadequate identification of the pathogen involved, it is important to investigate the etiological causes of abortion the herds for better understanding the causes of pregnancy issues and monitoring their occurrence. In addition, the absence of pathognomonic lesions in the tissues investigated in the histopathological analyses observed in this study strongly suggests that well-known etiological agents commonly associated to abortion, such as Leptospira spp., Toxoplasma spp., Chlamydia spp. and Neospora caninum, are unlikely to be the cause of infection of the analyzed fetuses. Taking this into account, the presence of $C$. fetus in the abomasal fluid samples from two bovine fetuses demonstrated in the present study suggests the possible association of $\mathrm{Cfv}$ not only with infertility, but also with cases of bovine abortion, highlighting the importance of investigating unusual causal agents of abortions in sheep and cattle. Overall, an adequate diagnosis is essential for establishing better prevention strategies to avoid the circulation of abortion-related infectious agents in the herds.
\end{abstract}

Keywords: campylobacteriosis, molecular diagnosis, venereal disease, abortion, reproductive disease. 


\section{INTRODUCTION}

Pregnancy losses are a major concern in livestock industry causing great economic losses. In cattle, reproductive issues are commonly associated to Bovine virus diarrhea (BVD), Brucellosis, Campylobacteriosis, Infectious Bovine Rhinotracheitis, Leptospirosis, Neosporosis, and Trichomoniasis [8,13]. In sheep, they are related to Chlamydial infection, Campylobacteriosis, Toxoplasmosis, Salmonellosis, Coxiellosis, Border Disease, and Cache Valley Disease [8].

Campylobacter fetus has 2 subspecies directly related to reproductive issues in ruminants: $C$. fetus subsp. fetus (Cff) and C. fetus subsp. venerealis (Cfv) [23]. They show high genetic similarity, but different epidemiological behaviors. Cff affects a wide range of hosts by colonizing their gastrointestinal tract, commonly related to ovine and bovine abortion, while $\mathrm{Cfv}$ is restricted to bovine genital tract leading to infertility cases mainly [21].

In cattle, abortions are generally associated with Cff, but can also result from bovine genital campylobacteriosis (BGC) caused by Cfv. Males are asymptomatic carriers and transmission may occur during the breeding. BGC is spread worldwide, thus the high circulation of Cfv leads to infertility and sporadic abortion [10,16,19,20,27].

In sheep, there are few reports about abortion associated to $C$. fetus or the occurrence of Cff infection $[6,9,12,22]$. In Brazil, only one study has been published lately about the occurrence of Cff in ovine gastrointestinal tract [14].

The present study aims to investigate the occurrence of $C$. fetus in bovine and ovine spontaneously aborted fetuses in order to introduce data about the occurrence of these pathogens in abortion in South Brazil.

\section{MATERIALS AND METHODS}

\section{Sample collection and processing}

A total of 30 spontaneously aborted bovine $(\mathrm{n}=$ $18)$ and ovine $(n=12)$ fetuses received for post mortem examination from June 2019 to December 2020 were included in this study. Farm and herd information were obtained with referring veterinarians and farm owners. During the necropsy, estimated gestational age was measured through the measurement of crown-rump length and gross lesions were recorded, when present. Sample collection and further analyses were performed according to Figure 1.

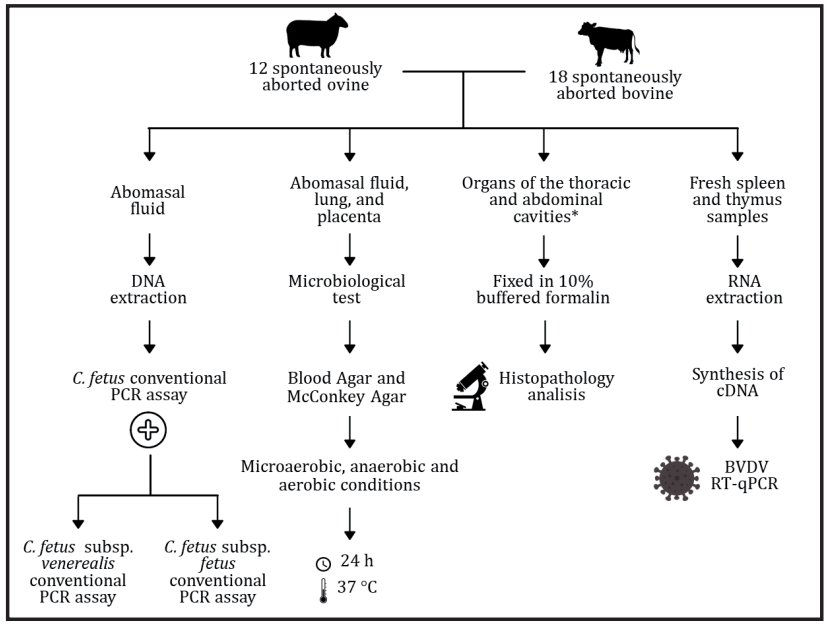

Figure 1. Workflow of the analyses: Abomasal fluid samples were collected from bovine and ovine fetuses for molecular diagnoses of Campylobacter fetus. Tissue samples were submitted to histopathological analyses, bacterial culture and RT-qPCR assays for BVDV detection.

Abomasum contents were collected with sterile syringes through puncture, being a fresh aliquot subjected to microbial culture in Blood Agar Base ${ }^{1}$ supplemented with $5 \%$ of ovine blood and MacConkey Agar $^{1}$ and incubated in micro-aerobic, anaerobic and aerobic conditions at $37^{\circ} \mathrm{C}$ for $48 \mathrm{~h}$. When available, fresh samples of lung and placenta were also cultivated.

Samples of the main organs of the thoracic and abdominal cavities, as well as the brain, skeletal muscle, eyelid, skin, and placenta, when available, were collected, fixed in $10 \%$ buffered formalin, routinely processed for histopathology and stained with hematoxylin ${ }^{2}$ and eosin ${ }^{3}$. Tissue sections were observed under light microscopy and histopathological lesions were recorded. Additionally, fresh spleen and thymus samples were collected for further RNA isolation for ruminant pestivirus detection.

\section{DNA isolation from abomasum content and}

Campylobacter fetus subsp. fetus and Campylobacter fetus subsp. venerealis detection by molecular analyses

Aliquots of $1 \mathrm{~mL}$ of abomasum content were used for DNA isolation. Samples were previously treated with $0.1 \mathrm{~V}$ of dithiothreitol (DTT) $0.2 \%$ and incubated at $37^{\circ} \mathrm{C}$ for $20 \mathrm{~min}$, in order to decrease viscosity. Then, samples were homogenized in vortex and cells were harvested by centrifugation at 11,000 $\mathrm{x}$ $g$ for $5 \mathrm{~min}$. DNA extraction was performed following of BIOPUR Mini Spin Plus Extraction Kit protocol $1^{4}$, including $10 \mu \mathrm{L}$ of RNAse $\mathrm{A}(10 \mathrm{ng} / \mu \mathrm{L})$ as indicated by 
the manufacturer instructions. Total DNA was eluted in $30 \mu \mathrm{L}$ of elution buffer.

Conventional PCR assays were performed in order to detect $C$. fetus (Table 1). Positive samples were further tested for subspecies identification, using primer sets for Cff and Cfv (Table 1). PCR assays were performed in $12 \mu \mathrm{L}$ reactions, using $1 \mathrm{U}$ Taq DNA polymerase ${ }^{5}$, Taq DNA Buffer $10 x, 50 \mathrm{mM}$ of $\mathrm{MgCl}_{2}$, $1 \mathrm{mM}$ of dNTP, $10 \mathrm{pmol}$ of each primer, and $50 \mathrm{ng}$ of DNA. Amplification conditions comprised: an initial denaturation at $95^{\circ} \mathrm{C}$ for $3 \mathrm{~min}$; followed by 35 cycles of $95^{\circ} \mathrm{C}$ for $20 \mathrm{~s}$, melting temperature as indicated in Table 1 for $20 \mathrm{~s}$, and $72^{\circ} \mathrm{C}$ for $2 \mathrm{~min}$; and a final exten- sion step at $72^{\circ} \mathrm{C}$ for $10 \mathrm{~min}$. Strains Cff ATCC 27374 and Cfv ATCC 19438 were used as positive controls.

RNA isolation from abomasum content and ruminant pestivirus detection by molecular analyses

Total RNA was isolated using Quick-Zol ${ }^{6}$ according to the manufacturer's instructions. cDNA synthesis and PCR were performed using a GoScript ${ }^{\mathrm{TM}}$ Reverse Transcription System and GoTaq G2 Hot Start Polymerase ${ }^{7}$. The PCR amplification resulted in a product of $118 \mathrm{bp}$ of 5 UTR of ruminant pestivirus that include Bovine Viral Diarrhea Virus-1 (BVDV-1), BVDV-2, Border Disease Virus (BDV), and HoBi-like pestivirus [26].

Table 1. PCR primers and targets for Campylobacter fetus, Campylobacter fetus subsp. fetus (Cff) and Campylobacter fetus subsp. venerealis (Cfv).

\begin{tabular}{|c|c|c|c|c|c|c|}
\hline Campylobacter target & Code & Target gene & $\begin{array}{l}\text { Primer sequence } \\
\quad\left(5^{\prime} \text { to } 3^{\prime}\right)\end{array}$ & $\begin{array}{l}\text { Product } \\
\text { length (bp) }\end{array}$ & $\mathrm{Tm} *\left({ }^{\circ} \mathrm{C}\right)$ & Reference \\
\hline \multirow{2}{*}{ C. fetus } & CAMPG-F & \multirow{2}{*}{ nahE } & GGTTATTTTTTATAACTGTAGGAATGCAGAT & \multirow{2}{*}{390} & \multirow{2}{*}{54} & \multirow{2}{*}{ [1] } \\
\hline & CAMPG-R & & GATCGCTTAAATCTTGTACTTTTAGCTTTT & & & \\
\hline \multirow{2}{*}{$C f f * *$} & MG3F & \multirow{2}{*}{$\operatorname{cst} \mathrm{A}$} & GGTAGCCGCAGCTGCTAAGAT & \multirow{2}{*}{960} & \multirow{2}{*}{52} & \multirow{2}{*}{ [11] } \\
\hline & MG4R & & TAGCTACAATAACGACAACT & & & \\
\hline \multirow{2}{*}{$C f v^{* * *}$} & CVEN-F & \multirow{2}{*}{ ISCfe 1} & GGTGGAGAGCGTAGATATAAATTAG & \multirow{2}{*}{455} & \multirow{2}{*}{52} & \multirow{2}{*}[5,24]{} \\
\hline & CVEN-R & & CCATAAAGCCTAGCTGAAAAAACTG & & & \\
\hline
\end{tabular}

*Melting temperature (Tm). **Campylobacter fetus subsp. Fetus. ***Campylobacter fetus subsp. venerealis.

\section{RESULTS}

A total of 30 spontaneously aborted bovine (18) and ovine fetuses (12) were analyzed in the current study, in which Campylobacter fetus was detected by molecular analyses in $2(6.6 \%)$ abomasal fluid samples. C. fetus was identified only in 2 bovine fetuses, named F1 and F2 (Table 2). The samples from fetuses F1 and $\mathrm{F} 2$, which were positive to the $C$. fetus $\mathrm{PCR}$ reactions, were then subjected to PCR assays for Cff and Cfv detection, in order to identify which subspecies was involved in the abortion. After that, we detected $\mathrm{Cfv}$ in both fetuses by subspecies PCR assays (Table 3).

Both fetuses were third-trimester male calves (7 months of gestation), referred from farms located in the state of Rio Grande do Sul, South Brazil (Table $3)$. The farm of fetus F1 was an extensive cow-calf operation, with 600 breeding cows. Reproductive management used to be conducted with fixed-time artificial insemination, and bulls were used to breed empty cows only. The farm owner reported $10 \%$ of embryonic losses from 30 to 60 days of gestation and several third-trimester abortions between 2018 and 2019. The farm of fetus F2 was a dairy operation with 170 cows housed in a free-stall barn. All cows were artificially inseminated, and nine abortions were recorded in 2019.

In farms of fetuses F1 and F2, vaccination was conducted against Bovine Infectious Rhinotracheitis, Bovine Viral Diarrhea Virus (BVDV), Parainfluenza type 3 (PI3), Bovine Respiratory Syncytial Virus (BRSV), and Leptospira interrogans serovars Canicola, Grippotyphosa, Hardjo, Icterohaemorrhagiae, and Pomona. No vaccination against $C$. fetus used to be conducted in both farms.

At post mortem examination, fetuses $\mathrm{F} 1$ and F2 were moderately and mildly autolyzed, respectively. None of the samples from both fetuses submitted for microbiological culture presented significant bacterial growth. In addition, both fetuses had negative PCR results for ruminant pestivirus (Table 3). The macroscopic and microscopic changes found in the Cfv-positive animals (F1 and F2) were not 
either specific or directly related to Campylobacter infections. In F1 was observed moderate deposition of friable yellowish material in cotyledons, discrete multifocal necrosis of the chorionic epithelium of the placenta associated with deposition of cell debris and discrete inflammatory infiltrate of lymphocytes and macrophages, discrete multifocal inflammatory infiltrate of lymphocytes and macrophages in alveolar spaces of the lungs and moderate accumulation of intra-alveolar golden granular pigment (meconium), and: marked diffuse autolysis in liver and spleen. No alteration was observed in F2.

Table 2. PCR results for Campylobacter fetus, C. fetus subsp. fetus and C. fetus subsp. venerealis from abomasal fluid from aborted bovine and ovine fetuses.

\begin{tabular}{ccccc}
\hline Animal & Positive for C. fetus & Negative for C. fetus & Positive for C. fetus subsp. fetus & Positive for C. fetus subsp. venerealis \\
\hline Cattle & 2 & 16 & 0 & 2 \\
Sheep & 0 & 12 & 0 & 0 \\
\hline Total & 2 & 28 & 0 & 2 \\
\hline
\end{tabular}

Table 3. Overview information of the Campylobacter fetus subsp. venerealis-positive fetuses.

\begin{tabular}{ccccccc}
\hline Fetus ID & Specie & Gender & Breed & Gestational age & RT-PCR BVDV & Microbiological test \\
\hline F1 & Bovine & Male & Angus & 7 months & ND & No growth \\
F2 & Bovine & Male & Holstain & 7 months & ND & No growth \\
\hline
\end{tabular}

Gestational age was an estimative. ND: indicates pestivirus was not detected in the analysed sample by RT-PCR.

\section{DISCUSSION}

Diagnostic rates of abortion in cattle and sheep reported by different studies are highly variable. Complementary tests significantly impact on greater diagnosis proportion [4]. However, reaching a final diagnosis is still a challenging task, leading to an inconclusive diagnose for the majority of spontaneously abortion cases in ovine and bovine due to incorrect sampling or difficulties in the agent identification and serological testing $[2,28]$. Thus, investigating the etiologic cause of abortion is recommended for better understanding the causes of pregnancy issues and monitoring their occurrence. Therefore, expanding the search for pathogens and further identifying the causal agents of abortions is essential for implementing management and prevention measures to avoid economic losses in sheep and cattle industry due to pregnancy losses.

It was observed the occurrence of $\mathrm{Cfv}$ in $11.1 \%$ of the investigated bovine fetuses, while Cff was not detected in any sample. Worth mentioning that $\mathrm{Cfv}$, despite being the causal agent of BGC, is rarely directly associated to abortions. A previous report [3] investigating the occurrence of $C$. fetus in natural cases of bovine and ovine abortions by immunohistochemical assay detected antigens for Cff in $50 \%$ ovine and in $4.5 \%$ bovine cases, while $\mathrm{Cfv}$ antigen was detected in bovine, totalizing $59 \%$ of bovine abortion cases. In South America, Cfv have been associated to $2.0 \%$ of aborted fetuses in Uruguay [15] and in $9.33 \%$ of bovine abortions in Argentina [18].

Moreover, C. fetus was not detected in none of the 12 ovine samples analyzed by PCR assay in the present study. Differently, a wide investigation of infectious agents associated with ovine abortion and stillbirths determined that Campylobacter spp. was associated to $10.3 \%$ of 1,784 cases, being Cff the most common species found $(7.0 \%)$ [12]. Nevertheless, other etiologic agents of pregnancy losses can be involved in the abortion, such as Toxoplasma gondii, Chlamydia psittaci, Trueperella pyogenes, Campylobacter jejuni, Salmonella sp., Pasteurella, Escherichia coli [12]. Interestingly, although Cff is described as a commonly associated infectious agent that causes abortions in sheep, there is limited information about its occurrence in South America. In the last 2 decades, only few studies have investigated Cff occurrence and relationship with ovine abortion cases, being held in Brazil [9], Argentina [7], and Uruguay [6]. Furthermore, Cff is consider an opportunistic human pathogen, which may lead to diarrhea, bacteremia, and pregnancy issues as well [25]; therefore, further 
investigation about the occurrence of this pathogen in cattle and ovine herd is required.

We highlight that some important causes of abortion in cattle could be excluded as causes, in this present study, because neither bacterial growth nor ruminant pestivirus identification were observed in both fetuses F1 and F2. Moreover, no microscopic finding indicative or pathognomonic of any infectious etiology was observed in fetuses F1 and F2. However, even those additional complementary results for agents such as Leptospira spp., Toxoplasma spp., Chlamydia spp., and Neospora caninum were not available; infection by these agents should be unlikely due to absence of lesions.

In both Cfv positive fetuses (F1 and F2), gross and microscopic evaluations were unremarkable. Pathological findings previously reported in cases of Campylobacter fetus-associated abortions include neutrophilic bronchopneumonia and interstitial pneumonia, fibrinosuppurative serositis, hepatitis, gastroenteritis, and neutrophilic and necrotic placentitis $[3,17]$. Nevertheless, macroscopic and microscopic findings are commonly not observed, being the pathological lesions associated with the high bacteria charge, which we could not presume in the studied cases. To the best of our knowledge, C. fetus is not a bacterium present in both fetuses and cow normal microbiota or without disease association; therefore, the molecular identification of $C$. fetus in aborted animals could be related to infectious abortion cases.

\section{CONCLUSION}

Our findings demonstrate de occurrence of Campylobacter fetus subsp. venerealis in spontaneously aborted cattle fetuses, illustrating its possible association in abortion cases in South Brazil. Overall, our results highlight the importance of investigating uncommon causal agents of abortions in sheep and cattle, in order to establish better prevention strategies to avoid infectious agents' circulation in the herd.

\section{MANUFACTURERS}

${ }^{1}$ Kasvi - Produtos e Equipamentos para Laboratórios. São José dos Pinhas, PR, Brazil.

${ }^{2}$ Êxodo Científica. Sumaré, SP, Brazil

${ }^{3}$ Neon Suzano. Suzano, SP, Brazil

${ }^{4}$ Mobius Life Science. Pinhais, PR, Brazil.

${ }^{5}$ QuatroG Pesquisa e Desenvolvimento Ltda. Porto Alegre, RS, Brazil.

${ }^{6}$ Ludwig Biotecnologia Ltda. Porto Alegre, Brazil.

${ }^{7}$ Promega Corporation. Madison, WI, USA.

Funding. This work was supported by the Coordenação de Aperfeiçoamento de Pessoal de Nível Superior (CAPES), finance code 001, and Conselho Nacional de Desenvolvimento Científico e Tecnológico (CNPq), Process no. 420590/2018-8 - CNPq-Universal/2018).

Acknowledgements. We thank Bruna Correa Lopes for her assistance in the histopathological analyses.

Declaration of interest. The authors report no conflicts of interest. The authors alone are responsible for the content and writing of paper.

\section{REFERENCES}

1 Abril C., Vilei E.M., Brodard I., Burnens A., Frey J. \& Miserez R. 2007. Discovery of insertion element ISCfe1: a new tool for Campylobacter fetus subspecies differentiation. Clinical Microbiology and Infection. 13(10): 993-1000. DOI: 10.1111/j.1469-0691.2007.01787.x

2 Barkallah M., Gharbi Y., Hassena A.B., Slima A.B., Mallek Z., Gautier M., Greub G., Gdoura R. \& Fendri I. 2014. Survey of infectious etiologies of bovine abortion during mid- to late gestation in dairy herds. PloS One. 9(3): e91549. DOI: 10.1371/journal.pone.0091549

3 Campero C.M., Anderson M.L., Walker R.L., Blanchard P.C., Barbano L., Chiu P., Martínez A., Combessies G., Bardon J.C. \& Cordeviola J. 2005. Immunohistochemical identification of Campylobacter fetus in natural cases of bovine and ovine abortions. Journal of Veterinary Medicine. B, Infectious Diseases and Veterinary Public Health. 52(3): 138-141. DOI: 10.1111/j.1439-0450.2005.00834.x

4 Clothier K. \& Anderson M. 2016. Evaluation of bovine abortion cases and tissue suitability for identification of infectious agents in California diagnostic laboratory cases from 2007 to 2012. Theriogenology. 85(5): 933-938. DOI: 10.1016/j.theriogenology.2015.11.001

5 De Carli S., Saggin B., Dias M.E., Lopes C.E., Dalto A.G.C., Rolim V.M., Zucco R., Pastre G., Borges J.B. \& Siqueira F.M. 2020. Frozen bovine preputial mucus as a suitable sample for the direct molecular diagnosis of Campylobacter fetus subsp. venerealis. Journal of Microbiological Methods. 179: 106101. DOI: 10.1016/j.mimet.2020.106101 
6 Dorsch M.A., Casaux M.L., Calleros L., Aráoz V., Caffarena R.D., Monesiglio C., Barcellos M., Da Silva Silveira C., Perdomo Y., Banchero G., Uzal F.A., Fraga M. \& Giannitti F. 2021. Placentitis and abortion caused by a multidrug resistant strain of Campylobacter fetus subspecies fetus in a sheep in Uruguay. Revista Argentina de Microbiologia. DOI: 10.1016/j.ram.2021.02.005

7 Fiorentino M.A., Stazionati M., Hecker Y., Morsella C., Cantón G, Harry H.R., Velilla A.V., Vaulet L.G., Fermepin M.R. \& Bedotti D.O. 2017. Campylobacter fetus subsp. fetus ovine abortion outbreak in Argentina. Revista Electrónica Veterinaria. 18(11): 1-11.

8 Givens M.D. \& Marley M.S.D. 2008. Infectious causes of embryonic and fetal mortality. Theriogenology. 70(3): 270-285. DOI: 10.1016/j.theriogenology.2008.04.018

9 Gressler L.T., Kirinus J.K., Machado G., Libardoni F. \& De Vargas A.C. 2012. Campylobacter fetus subespécie fetus: abortamento e natimortalidade em ovinos. Ciência Rural. 42: 697-700. DOI: 10.1590/S0103-84782012000400020

10 Hosseinzadeh S., Kafi M. \& Pour-Teimouri M. 2013. PCR detection of Campylobacter fetus subspecies venerealis in smegma samples collected from dairy cattle in Fars, Iran. Veterinary Research Forum. 4(4): 227-231.

11 Hum S., Quinn K., Brunner J. \& On S.L.W. 1997. Evaluation of a PCR assay for identification and differentiation of Campylobacter fetus subspecies. Australian Veterinary Journal. 75: 827-831. DOI: 10.1111/j.1751-0813.1997.tb15665.x

12 Kirkbride C.A. 1993. Diagnoses in 1,784 ovine abortions and stillbirths. Journal of Veterinary Diagnostic Investigation. 5(3): 398-402. DOI: 10.1177/104063879300500316

13 Lindsay D.S. \& Dubey J.P. 2020. Neosporosis, Toxoplasmosis, and Sarcocystosis in Ruminants: An Update. The Veterinary Clinics of North America. Food Animal Practice. 36: 205-222. DOI: 10.1016/j.cvfa.2019.11.004

14 Lúcio E.C, Borges J.M., Batista Filho A.F.B., Gouveia G.V., Costa M.M., Mota R.A. \& Pinheiro Junior J.W. 2018. Ocorrência de ovinos portadores da infecção por Campylobacter spp. no estado de Pernambuco. Pesquisa Veterinária Brasileira. 38(2): 262-270. DOI: 10.1590/1678-5150-PVB-4895

15 Macías-Rioseco M., Silveira C., Fraga M., Casaux L., Cabrera A. \& Francia M.E. 2020. Causes of abortion in dairy cows in Uruguay. Pesquisa Veterinária Brasileira. 40(5): 325-332. DOI: 10.1590/1678-5150-PVB-6550

16 Molina L.L., Angón E., García A., Caballero-Villalobos J., Giorgis A.O., Moralejo R.H. \& Perea J. 2018. A retrospective epidemiological analysis of shared risk factors for bovine trichomoniasis and bovine genital campylobacteriosis in La Pampa province (Argentina). Preventive Veterinary Medicine. 161: 109-114. DOI: 10.1016/j.prevetmed.2018.10.022

17 Morrell E.L., Barbeito C.G., Odeón C.A., Gimeno E.J. \& Campero C.M. 2011. Histopathological, immunohistochemical, lectinhistochemical and molecular findings in spontaneous bovine abortions by Campylobacter fetus. Reproduction in Domestic Animals. 46(2): 309-315. DOI: 10.1111/j.1439-0531.2010.01668.x

18 Morrell E.L., Campero C.M., Cantón G.J., Odeón A.C., Moore D.P., Odriozola E., Paolicchi F. \& Fiorentino M.A. 2019. Current trends in bovine abortion in Argentina. Pesquisa Veterinária Brasileira. 39(1): 12-19. DOI: 10.1590/16785150-PVB-5668

19 Sanhueza J.M., Heuer C., Jackson R., Hughes P., Anderson P., Kelly K. \& Walker G. 2014. Pregnancy rates of beef cattle are not affected by Campylobacter fetus subsp. venerealis real-time PCR-positive breeding sires in New Zealand. New Zealand Veterinary Journal. 62(5): 237-243. DOI: 10.1080/00480169.2014.898202

20 Silveira C.S., Fraga M., Giannitti F., Macías-Rioseco M. \& Riet-Correa F. 2018. Diagnosis of bovine genital campylobacteriosis in South America. Frontiers in Veterinary Science. 5: 321. DOI: 10.3389/fvets.2018.00321

21 Skirrow M.B. 1994. Diseases due to Campylobacter, Helicobacter and related bacteria. Journal of Comparative Pathology. 111(2): 113-149. DOI: 10.1016/s0021-9975(05)80046-5.

22 Uaboi-Egbenni P.O., Bessong P.O., Samie A. \& Obi C.L. 2010. Campylobacteriosis in sheep in farm settlements in the Vhembe district of South Africa. African Journal of Microbiology Research. 4(20): 2109-2117. DOI: 10.5897/ AJMR.9000139

23 van Bergen M.A., Dingle K.E., Maiden M.C., Newell D.G., van der Graaf-Van Bloois L., van Putten J.P. \& Wagenaar J.A. 2005. Clonal nature of Campylobacter fetus as defined by multilocus sequence typing. Journal of Clinical Microbiology. 43(12): 5888-5898. DOI: 10.1128/JCM.43.12.5888-5898.2005

24 van Der Graaf-van Bloois L., van Bergen M.A.P., van der Wal F.J., Boer A.G., Duim B., Schmidt T. \& Wagenaar J.A. 2013. Evaluation of molecular assays for identification Campylobacter fetus species and subspecies and development of a C. fetus specific real-time PCR assay. Journal of Microbiological Methods. 95(1): 93-97. DOI: DOI: 10.1016/j. mimet.2013.06.005 
G.M. Breyer, M.E. Dias, L.C. Henker, et al. 2021. Campylobacter fetus in Abomasal Fluid from Spontaneously Aborted Bovine and Ovine Fetuses. Acta Scientiae Veterinariae. 49: 1834.

25 Wagenaar J.A., van Bergen M.A.P., Blaser M.J., Tauxe R.V., Newell D.G. \& van Putten J.P.M. 2014. Campylobacter fetus infections in humans: exposure and disease. Clinical Infectious Diseases. 58(11): 1579-1586. DOI: 10.1093/cid/ ciu085

26 Weber M.N., Mósena A.C., Simões S.V., Almeida L.L., Pessoa C.R., Budaszewski R.F., Silva T.R., Ridpath J.F., Riet-Correa F., Driemeier D. \& Canal C.W. 2016. Clinical Presentation Resembling Mucosal Disease Associated with 'HoBi'-like Pestivirus in a Field Outbreak. Transboundary and Emerging Diseases. 63(1): 92-100. DOI: 10.1111/ tbed. 12223

27 Williams E.J. \& O'Donovan J. 2009. Ovine abortion: an overview. Irish Veterinary Journal. 62(5): 342-346.

28 Ziech R.E., Machado G., Kirinus J.K., Libardoni F., Kessler J.D., Pötter L. \& Vargas A.C. 2014. Campylobacter fetus in cattle from Rio Grande do Sul State, Brazil. Ciência Rural.44(1): 141-146. DOI: 10.1590/S0103-84782014000100023 